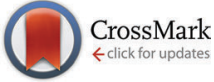

Cite this: J. Mater. Chem. B, 2016, 4, 2377

Received 20th January 2016, Accepted 8th March 2016

DOI: $10.1039 / \mathrm{c} 6 \mathrm{tb} 00178 \mathrm{e}$

www.rsc.org/MaterialsB

\section{Preparation of nanosized coacervates of positive and negative starch derivatives intended for pulmonary delivery of proteins $\uparrow$}

\author{
S. Barthold, ${ }^{a b}$ S. Kletting, ${ }^{a b}$ J. Taffner, ${ }^{a}$ C. de Souza Carvalho-Wodarz, ${ }^{a}$ E. Lepeltier, ${ }^{a}$ \\ B. Loretz $z^{\star a}$ and C. - M. Lehr ${ }^{\text {ab }}$
}

\begin{abstract}
Proteins and peptides represent a large fraction of the compounds currently in drug development pipelines. Their application however often depends on the use of carrier systems. Nanoparticles (NPs) are widely used such carrier systems for protein delivery. The aim of this study was to design a new drug delivery system (DDS), prepared under mild conditions in aqueous solution without the requirement of a stabilizer. The biodegradability and biocompatibility of the designed system was explored with a view to specifically determine its potential to facilitate the pulmonary delivery of proteins. As a first step, anionic and cationic water soluble starch-derivatives were synthesized. These starch polymers allowed for NP formation via coacervation, as well as protein loading. Physicochemical characterization of the prepared NPs was then carried out: NPs were found to have a narrow size distribution with an average size ranging from 140 to $350 \mathrm{~nm}$, and a $\zeta$-potential ranging from -10 to $-35 \mathrm{mV}$, depending on the formulation conditions. In a proof of concept study, starch NPs were found to be readily degraded by the human enzyme $\alpha$-amylase, and showed good biocompatibility with A549 cells after $4 \mathrm{~h}$. Upon nebulization, NPs were seen to be internalized by air-liquid interface cultivated A549 cells as well as $16 \mathrm{HBE} 140^{-}$cells. To evaluate the ability of starch NPs to load proteins of various characteristics, NPs were loaded with four model proteins/peptides possessing different molecular weights and isoelectric points - IgG1, RNAse A, insulin, and vancomycin. The greatest loading was achieved in the case of vancomycin with up to $23 \%$ drug loading and $43 \%$ encapsulation efficiency, indicating an optimal loading of proteins with an isoelectric point close to the $\mathrm{pH}$ of the NP suspension. In conclusion, starch NPs prepared by the developed mild and straightforward technique show potential as a safe platform for pulmonary delivery of proteins and peptides.
\end{abstract}

\section{Introduction}

Proteins and peptides represent a large fraction of the compounds currently in drug development pipelines, ${ }^{1,2}$ due to their high selectivity and predictable activity profiles. However, the successful delivery of such biopharmaceuticals is anything but easy.

\footnotetext{
${ }^{a}$ Department Drug Delivery, Helmholtz-Institute for Pharmaceutical Research Saarland (HIPS), Helmholtz-Centre for Infection Research (HZI), Saarbrücken, Germany.E-mail: Brigitta.Loretz@helmholtz-hzi.de

${ }^{b}$ Department of Pharmacy, Saarland University, Saarbrücken, Germany

$\dagger$ Electronic supplementary information (ESI) available: Fig. S1: ${ }^{1} \mathrm{H}-\mathrm{NMR}$ of starch derivatives in $\mathrm{D}_{2} \mathrm{O}$. Fig. S2: GPC analysis of starch derivatives. Fig. S3: XRPD pattern of starch derivatives. Fig. S4: Stability study of starch NPs at RT or in the fridge. Fig. S5: FT-IR of unlabeled PosSt (black) and labeled PosSt $t_{\mathrm{F}}$. Fig. S6: Confocal laser scanning microscopy (CLSM) images of $250 \mu \mathrm{L}$ nebulized starch NP onto A549 cultivated under ALI. Incubation was at $4{ }^{\circ} \mathrm{C}$ for $1 \mathrm{~h}$ (A) or $4 \mathrm{~h} \mathrm{(B).}$ Table S1: Characteristics of starch NPs prepared with different amounts of labeled PosSt $t_{\mathrm{F}}$ in a molar ratio of 1:1 $\left(\operatorname{PosSt}_{(\mathrm{F})}\right.$ : NegSt) and a concentration of $0.25 \mathrm{mg} \mathrm{mL}^{-1}$. See DOI: $10.1039 / \mathrm{c} 6 \mathrm{tb} 00178 \mathrm{e}$
}

The oral route of administration for example, although wellknown and successful for small molecule drugs, presents significant challenges in the case of protein delivery. In contrast to small molecule drugs, proteins are characterized by a complex (and degradation-prone) secondary and tertiary structure, which is vital for their biological activity; proteins also possess a high molecular weight, meaning a low permeability across biological barriers., ${ }^{3,4}$ As a result, most protein and peptide formulations available on the market today are administered intravenously to overcome difficulties associated for example with oral delivery, such as enzymatic degradation and poor permeability. However, modern pharmaceutical technology has made significant progress in the design of non-invasive drug delivery strategies that act to stabilize protein during formulation and storage, and to maintain efficacy of the protein throughout the delivery process itself. ${ }^{5-7}$

Besides the oral route, one of the most promising noninvasive routes of administration is the pulmonary route. 
Due to reduced systemic side effects and a rapid onset of action, administration via the lungs represents a valuable means of local drug delivery for treatment of diseases such as asthma, cystic fibrosis and lung cancer.

The use of nanoparticles (NPs) as drug delivery systems (DDS) for protein delivery is well-known. NPs offer several advantages over conventional therapeutic systems. The incorporation of proteins into NPs can be beneficial for their stability and can offer protection during storage and administration. Moreover, NPs are known to facilitate an enhanced cellular uptake of incorporated or associated actives, which could also be beneficial in the case of protein permeation through epithelial barriers. ${ }^{8}$

While several polymers have been investigated for use as components of DDS, the need for natural and semi-synthetic polymers with beneficial properties specifically for the delivery of proteins is increasing. PLGA for example has been widely utilized; however, although biodegradable mainly by hydrolytic degradation, the use of such a polymer in the case of a proteinDDS could prove detrimental to the encapsulated cargo, due to high generated levels of acidic degradation products. ${ }^{9}$ In addition to the commonly used PLGA, polysaccharides are among the most studied polymers for drug delivery applications. ${ }^{10}$ Alginate, for example, can form NPs of a wide size range, based on a controlled gelification process of alginate by calcium ions. ${ }^{11}$ Chitosan-based systems are also well explored and characterized. ${ }^{12-16}$ Here again a polymer (chitosan) is interacting with a small ionic crosslinker, tripolyphosphate (TPP). Although chitosan is enzymatically degradable by chitosanase, ${ }^{17,18}$ this is not an enzyme that is ubiquitous in the human body. Starch, in contrast, is biocompatible, non-toxic, and readily degraded by $\alpha$-amylase, a human enzyme. As such, it offers great potential as an excipient for DDS preparation. Moreover, the high amount of hydroxyl groups present within starch allows for different derivatizations. The use of propyl starch for the encapsulation of small compounds was for example studied by SantanderOrtega. ${ }^{19}$ Particles in this work were prepared by an emulsification diffusion technique; however, the use of ethyl acetate and a high speed homogenizer makes this preparation method challenging for the encapsulation of proteins, which are prone to degradation under these conditions. Another study from Yamada et al. has shown the formation of polyplexes from positively charged PEI-derivatized starch with pDNA, for improved transfection. ${ }^{20}$ Thiele et al. investigated the formulation of NPs for targeted cancer therapy by the coacervation of a derivatized anionic starch copolymer, linked with pteroic acid as cellspecific ligand, and a cationic cyclodextrin. In this work, the small ionic crosslinker as used for the systems of alginate and chitosan was replaced by a second polymer. $^{21}$

The aim of this work was to prepare NPs via coacervation in aqueous medium from two oppositely charged starch derivatives, in order to take advantage of the excellent biocompatibility and biodegradability of these natural polymers. An anionic and a cationic starch derivative were first synthesized, as such compounds were hypothesized to readily facilitate the subsequent formation of NPs, suitable for loading of proteins with a range of sizes and charges.

\section{Experimental section}

\section{Materials}

Partially hydrolyzed potato starch $\left(M_{\mathrm{w}} 1300000 \mathrm{~g} \mathrm{~mol}^{-1}\right.$, approx. $33 \%$ amylose content) was a gift from AVEBE (Netherlands). Negatively (NegSt) and positively (PosSt) charged starches were synthesized with a weight average molecular weight of 87000 and 76000 , respectively. IgG1 and insulin were kindly donated by Boehringer Ingelheim (Germany) and Sanofi (France), respectively. Vancomycin hydrochloride (vancomycin), Ribonuclease A from bovine pancreas (RNAse A), $\alpha$-amylase from porcine pancreas and thiazolyl blue tetrazolium bromide (MTT reagent) were bought from Sigma Aldrich (USA). Bodipy ${ }^{\circledR}$ FL-C5 NHS Ester (succinimidyl ester), cell culture medium (RPMI 1640, minimum essential medium eagle (MEM)), fetal bovine serum (FBS), phosphate buffered saline (PBS) and Hank's balanced salt solution (HBSS) were obtained from Life Technologies (USA). Non-essential amino acids (NEAA) were sourced from GE Healthcare LifeSciences. A549 cells (No. CCL-185) were purchased from American Type Culture Collection. $16 \mathrm{HBE}^{-14 \mathrm{o}^{-}}$cells were a kind gift from $\mathrm{Dr}$ Dieter C. Gruenert (Department of Otolaryngology, University of California, San Francisco, CA, USA). Purified water was produced by a Milli-Q water purification system (Merck Millipore, USA). All other reagents were of analytical grade.

\section{Synthesis of starch derivatives}

Negatively charged starch (NegSt) was synthesized via oxidation of potato starch. ${ }^{21,22}$ Briefly, $20 \mathrm{~g}$ of dried potato starch was suspended in $800 \mathrm{~mL}$ of purified water and heated at $95{ }^{\circ} \mathrm{C}$ for one hour. After cooling down to room temperature (RT), TEMPO ((2,2,6,6-tetramethylpiperidin-1-yl)oxidanyl; $4 \mathrm{mg} \mathrm{g}^{-1}$ potato starch) was added to the suspension. $112 \mathrm{~mL}$ of sodium hypochlorite solution $(12 \%)$ was then added $\left(1 \mathrm{~mL} \mathrm{~min}^{-1}\right)$. During the addition of the sodium hypochlorite solution, the $\mathrm{pH}$ was kept at 8.5 by adding $1 \mathrm{M}$ sodium hydroxide. To stop the reaction, sodium borohydride was slowly added. The resulting solution was stirred overnight and purified by ultrafiltration (Vivaflow 200; $5 \mathrm{kDa}$ Hydrosart membrane, Sartorius Stedim Biotech GmbH, Germany). The product was dried by lyophilization (Alpha 2-4, Martin Christ $\mathrm{GmbH}$, Germany). For the synthesis of PosSt, $13 \mathrm{~g}$ of NegSt (free acid form) was dissolved in $650 \mathrm{~mL}$ DMSO at $50{ }^{\circ} \mathrm{C}$ under a reflux condenser, with stirring overnight. Coupling reagents $N, N^{\prime}$-dicyclohexylcarbodiimide (DCC) and 1-hydroxybenzotriazole (HOBt; each 1.5 molar equivalents, according to the degree of oxidation of NegSt) were then added and stirred for another $24 \mathrm{~h}$. Subsequently, 10 molar equivalents of ethylenediamine (according to the degree of oxidation of NegSt) were slowly added. The reaction was continued for $48 \mathrm{~h}$ at $50{ }^{\circ} \mathrm{C}$, with stirring. After filtration, the solution was lyophilized, subsequently dissolved in water, subject to extensive ultrafiltration (Vivaflow 200; $5 \mathrm{kDa}$ Hydrosart membrane, Sartorius Stedim Biotech GmbH, Germany) and again lyophilized.

\section{Characterization of starch derivatives}

Fourier transform infrared (FT-IR) measurements were carried out in solid state with a Spectrum 400 FT-IR/FT-NIR spectrometer 
(PerkinElmer, UK) between 600 and $4000 \mathrm{~cm}^{-1} \cdot{ }^{1} \mathrm{H}-\mathrm{NMR}$ spectra were collected at room temperature on a Bruker Biospin spectrometer NMR Magnet System $400 \mathrm{MHz}$ Ultrashield plus (Bruker, USA) in $\mathrm{D}_{2} \mathrm{O}$ (64 scans). The weight average molecular weights of starch derivatives were analysed by gel permeation chromatography (GPC, HLC-8320 GPC, Tosoh, Japan), equipped with online viscometer (ETA-2010, PSS, Germany) on SUPREMA 1000 and 30 columns (NegSt) or SUPREMA-MAX 1000 and 30 columns (PosSt) (PSS, Germany). A flow rate of $1 \mathrm{~mL} \mathrm{~min}^{-1}$ at $35{ }^{\circ} \mathrm{C}$ in $1 \mathrm{M}$ sodium nitrate (NegSt) or 1\% formic acid (PosSt) was employed. Calibration was performed with Pullulan and PVP standards. The degree of oxidation of NegSt was determined with the Blumenkrantz assay, a colorimetric method which detects uronic acid content. ${ }^{23} \mathrm{X}$-ray scans were taken by a diffractometer of the type Bruker D8 Advance, equipped with a 1D-detector 'Lynxeye' and variable divergence slit, using $\mathrm{CuK} \alpha$ radiation.

\section{Preparation of starch nanoparticles}

Starch NPs were prepared by charge-mediated coacervation between positively charged amine groups (PosSt) and negatively charged carboxylate groups (NegSt) of starch derivatives in aqueous solution. Briefly, materials were dissolved in purified water to obtain solutions of $1 \mathrm{mg} \mathrm{mL}^{-1}, 0.5 \mathrm{mg} \mathrm{mL} \mathrm{m}^{-1}$ and $0.25 \mathrm{mg} \mathrm{mL}^{-1}$ and filtered. Different molar ratios $(1: 3,1: 1,3: 1)$ of NegSt and PosSt solutions were prepared by adding adequate volumes of NegSt $\left(1,0.5,0.25 \mathrm{mg} \mathrm{mL} \mathrm{mL}^{-1}\right)$ solution to PosSt solution $\left(1,0.5,0.25 \mathrm{mg} \mathrm{mL}^{-1}\right)$ under gentle stirring at RT. NPs formed spontaneously and were analyzed after $15 \mathrm{~min}$ of stirring for equilibration. The final $\mathrm{pH}$ value of all tested formulations was 7.4.

\section{Physicochemical characterization of nanoparticles}

Particle size, size distribution (PdI), and $\zeta$-potential of starch NPs in preparation medium were determined using the Zetasizer Nano ZSP (Malvern Instruments, UK) with a scattering angle of $173^{\circ}$. Particle sizes were intensity based $z$-average values and standard deviation was of 3 measurements. Morphology of NPs was analyzed by transmission electron microscopy (TEM) using a JEOL JEM 2011 microscope (Oxford Instruments, UK). $20 \mu \mathrm{L}$ of sample was incubated on a copper grid for $30 \mathrm{~min}$. After positive staining with $1 \%(\mathrm{w} / \mathrm{v})$ of phosphotungstic acid (PTA) for $30 \mathrm{~s}$, samples were dried overnight (excess fluid was directly removed with filter paper) and analyzed. Physicochemical stability of NPs was monitored with respect to size, PdI and $\zeta$-potential for 14 days. Samples were stored either at RT $\left(21^{\circ} \mathrm{C}\right)$ or in the fridge $\left(\mathrm{F}, 4^{\circ} \mathrm{C}\right)$.

\section{Biodegradability of starch nanoparticles}

To study the biodegradation of starch NPs, $10 \mathrm{~mL}$ of NP suspension was incubated with $25 \mu \mathrm{L} \alpha$-amylase solution (36.37 units per $\mu \mathrm{L}$ ) at $37{ }^{\circ} \mathrm{C}$ for $2 \mathrm{~h}, 4 \mathrm{~h}, 6 \mathrm{~h}$, and $8 \mathrm{~h}$ under gentle stirring. As control, $10 \mathrm{~mL}$ of starch NP suspension was incubated at $37{ }^{\circ} \mathrm{C}$ under gentle stirring. Particle concentrations were then analyzed by nanoparticle tracking analysis (NanoSight LM 10, Malvern Instruments, UK). For the measurement, 0.5 mL was taken from each sample. Results shown are the particle concentration (after correction for the dilution factor needed for valuable measurement) of treated and nontreated samples (each $n=3$ ), respectively.

\section{Synthesis of fluorescently labeled PosSt $\left(\operatorname{PosSt}_{\mathrm{F}}\right)$}

For uptake studies of starch NPs into A549 and 16HBE140 cells, PosSt was labeled with Bodipy ${ }^{\circledR}$ FL-C5 NHS Ester. Briefly, $30 \mathrm{mg}$ of polymer was dissolved in $5 \mathrm{~mL}$ purified water and diluted slowly with $5 \mathrm{~mL}$ of methanol. $2 \mathrm{~mL}$ of Bodipy ${ }^{\circledR}$ FL-C5 NHS Ester solution in methanol $\left(0.5 \mathrm{mg} \mathrm{mL}^{-1}\right)$ was added slowly to obtain a molar ratio starch: dye of $50: 1$. The sample was stirred for one hour at RT under light protection and precipitated afterwards with $1 \mathrm{M}$ sodium hydroxide and ethanol. Washing was performed with ethanol:methanol $(1: 1)$ until the supernatant did not show any fluorescence. Coupled starch was then dissolved in purified water and freeze dried.

\section{Nanoparticle preparation with fluorescently labeled PosSt}

For uptake studies, solutions of $0.25 \mathrm{mg} \mathrm{mL}^{-1}$ and a molar ratio of 1:1 of PosSt: NegSt were chosen. Rather than PosSt alone, a 1:1 mixture of PosSt $\mathrm{F}_{\mathrm{F}}$ : PosSt was used for particle preparation.

\section{Stability of nanoparticles upon aerosolization}

To study the aerosolization behaviour of starch NPs, starch 0.25-1: 1 was nebulized with the AeronebLab nebulizer (Aerogen Ltd, Ireland) and collected to be analyzed for size, PdI and $\zeta$-potential with the Zetasizer Nano ZSP (Malvern Instruments, UK).

\section{Cell culture}

A549 cells were cultivated in RPMI 1640 medium containing $10 \%$ FBS (v/v). For the conduction of cell experiments, A549 cells were seeded into 96 well plates (cell viability assay) or Transwell ${ }^{\circledR}$ plates $\left(3460,1.12 \mathrm{~cm}^{2}\right.$; uptake studies). To test the uptake also with a non-cancer cell line of bronchial origin, $16 \mathrm{HBE} 14 \mathrm{o}^{-}$cells were used. These cells were cultivated in MEM medium containing $10 \%$ FBS (v/v), 1\% NEAA and $300 \mathrm{mg}$ of glucose. 1\% (v/v) Penicillin/Streptomycin (P/S, $10000 \mathrm{U} \mathrm{mL}^{-1}$, Gibco life technologies, USA) was added to each medium before cell viability and uptake studies.

\section{Cell viability studies}

Cell viability was evaluated by using the 3-(4,5-dimethylthiazol2-yl)-2,5-diphenyltetrazolium bromide (MTT)-assay. $2 \times 10^{5}$ cells were seeded into 96 well plates. The assay was performed at $90 \%$ confluence. Cell medium was removed and cells were washed once with $200 \mu \mathrm{L}$ HBSS (composed of $1.12 \mathrm{mM} \mathrm{CaCl}_{2}$, $0.49 \mathrm{mM} \mathrm{MgCl}_{2} \cdot 6 \mathrm{H}_{2} \mathrm{O}, 0.41 \mathrm{MgSO}_{4} \cdot 7 \mathrm{H}_{2} \mathrm{O}, 5.33 \mathrm{mM} \mathrm{KCl}$, $0.44 \mathrm{mM} \mathrm{KH}_{2} \mathrm{PO}_{4}, 4.17 \mathrm{mM} \mathrm{NaHCO}, 137.93 \mathrm{mM} \mathrm{NaCl}, 0.34 \mathrm{mM}$ $\mathrm{Na}_{2} \mathrm{HPO}_{4}, 5.55 \mathrm{mM}$ D-Glucose, $\mathrm{pH}$ 7.4). Cells were incubated with starch NP suspension diluted with RPMI medium, PosSt or NegSt or water soluble potato starch, dissolved in RPMI medium (concentrations of 133, 67, 33, 17, and $8 \mu \mathrm{g} \mathrm{mL}{ }^{-1}$ ) for $4 \mathrm{~h}$ and $24 \mathrm{~h}$, respectively. Afterwards, the supernatant was aspirated and the cells were washed once with $200 \mu \mathrm{L}$ HBSS buffer. $100 \mu \mathrm{L}$ fresh HBSS buffer, containing 10\% (v/v) MTT reagent $\left(5 \mathrm{mg} \mathrm{mL}^{-1}\right)$ was added and incubated for further $4 \mathrm{~h}$. HBSS buffer was aspirated and $100 \mu \mathrm{L}$ DMSO was added and 
incubated for $20 \mathrm{~min}$. Absorbance was measured at $550 \mathrm{~nm}$ with the Tecan Infinite ${ }^{\mathbb{R}} 200$ microplate reader (Tecan Deutschland $\mathrm{GmbH}$, Germany). All incubation steps were done at $37^{\circ} \mathrm{C}$, under gentle shaking and light protection. Cell viabilities were calculated in comparison to negative control (untreated cells as 100\% value of cell viability) and positive control (1\% TritonX-100 solution as $0 \%$ value of cell viability).

\section{Uptake of starch nanoparticles into pulmonary cell lines}

For the evaluation of starch NP uptake into A549 and $16 \mathrm{HBE} 4 \mathrm{o}^{-}$cells, $1 \times 10^{5}$ and $0.6 \times 10^{5}$ cells per well, respectively, were seeded on a Transwell ${ }^{\circledR}$ membrane. After $24 \mathrm{~h}$ A549 cells were transferred to the air-liquid interface (ALI), i.e. medium was aspirated, and $500 \mu \mathrm{L}$ of fresh medium was added to the basolateral compartment only. Two days later $250 \mu \mathrm{L}$ of labeled starch NPs were deposited onto A549 cells with the AeronebLab nebulizer (Aerogen Ltd, Ireland). 16HBE14o ${ }^{-}$ cells were transferred to ALI after $48 \mathrm{~h}$ in culture. $250 \mu \mathrm{L}$ starch NPs were nebulized as for deposition on A549 or $16 \mathrm{HBE}^{-14 \mathrm{o}^{-}}$cells, respectively. In both cases, after $1 \mathrm{~h}, 4 \mathrm{~h}$ or $24 \mathrm{~h}$ of incubation at $37{ }^{\circ} \mathrm{C}$, cells were washed with PBS and fixed with $3 \%$ paraformaldehyde (PFA) for $30 \mathrm{~min}$ at RT. After fixation, cells were permeabilized with a BSA/saponin solution, followed by an anti-phalloidin (actin) staining (1:143 in A549 and 1:100 in $16 \mathrm{HBE} 14 \mathrm{o}^{-}$in $\mathrm{PBS} / \mathrm{BSA} / \mathrm{saponin}$ ) for $30 \mathrm{~min}$. After washing, the samples were counterstained with nuclei-staining DAPI (1:50 000 in PBS) and subsequently mounted with DAKO mounting medium (DAKO, USA). The samples were analyzed by a confocal laser scanning microscope (Zeiss LSM710, Zeiss, Germany). Lasers at $405 \mathrm{~nm}$ (DAPI), $488 \mathrm{~nm}$ (starch NPs) and $633 \mathrm{~nm}$ (actin) were used for detection. Microscopic images of fixed samples were acquired at $1024 \times 1024$ resolution, using a $63 \times$ water immersion objective and $z$-stacks of $6 \mu \mathrm{m}$. Confocal images were analyzed using Zen 2012 software (Carl Zeiss Microscopy $\mathrm{GmbH}$ ) and Fiji Software (a distribution of ImageJ, available at http://fiji.sc).

\section{Loading of starch nanoparticles with proteins/peptides}

In order to assess the use of starch NPs as DDS, a typical test set of four proteins varying in size, net charge, and hydrophilicity were chosen for loading experiments. Proteins that could actually act as active pharmaceutical ingredients (API) were chosen for use, rather than model proteins (such as ovalbumin (OVA) or bovine serum albumin (BSA)). In detail, these proteins were IgG1 ( $M_{\mathrm{w}}: 150 \mathrm{kDa}$, IEP: 8.5), RNAse A ( $M_{\mathrm{w}}: 14 \mathrm{kDa}$, IEP: 9.6), insulin $\left(M_{\mathrm{w}}: 6 \mathrm{kDa}\right.$, IEP: 5.3$)$, and vancomycin $\left(M_{\mathrm{w}}: 1.5 \mathrm{kDa}\right.$, IEP: 7.5). For the loading experiments, each protein sample was prepared as $5 \mathrm{mg} \mathrm{mL} \mathrm{mL}^{-1}$ stock solution in purified water, and added to the NP suspension to obtain final protein concentrations of $17.2 \mu \mathrm{g} \mathrm{mL}^{-1}, 34.2 \mu \mathrm{g} \mathrm{mL}^{-1}$, and $51.2 \mu \mathrm{g} \mathrm{mL}^{-1}$.

\section{Loading efficiency}

For the determination of protein encapsulation efficiency (EE) and loading rate, NPs and unincorporated protein were separated, after 15 min equilibration, by ultracentrifugation $(45000 \times g$ for 90 min; Optima L-XP, Beckman Coulter, UK). The amount of free protein in the resulting supernatant was determined with a BCA (bicinchoninic acid) Assay Kit (Sigma Aldrich, USA). The principle of the assay relies on the formation of $\mathrm{Cu}^{2+}$-protein complexes that lead to the reduction of $\mathrm{Cu}^{2+}$ to $\mathrm{Cu}^{1+}$ under alkaline conditions. BCA then forms a purple complex with $\mathrm{Cu}^{1+}$ in alkaline conditions that can be detected by measurement of absorbance at $562 \mathrm{~nm}$; absorbance values can then be correlated to protein concentrations. EE and loading rate of proteins in the NPs were defined and calculated according to the following equations:

$$
\begin{gathered}
\mathrm{EE}[\%]=\frac{\operatorname{mass}(\text { protein })_{\text {total }}-\operatorname{mass}(\text { protein })_{\text {free }}}{\operatorname{mass}(\text { protein })_{\text {total }}} \times 100 \\
\text { Loading rate }[\%]=\frac{\operatorname{mass}(\operatorname{protein})_{\text {total }}-\operatorname{mass}(\operatorname{protein})_{\text {free }}}{\text { mass }_{\mathrm{NP}}} \times 100
\end{gathered}
$$

For the calculation of the particle yield (mass NPs), fixed volumes of NP suspension were filtered with Vivaflow 50 (100 kDa molecular weight cut off (MWCO), PES (Polyethersulfone) membrane, Sartorius, Germany), freeze dried and weighed.

\section{Results and discussion}

\section{Synthesis and characterization of starch derivatives}

The raw material used for the synthesis of starch derivatives was a partially hydrolyzed potato starch with a molecular weight of $1300000 \mathrm{~g} \mathrm{~mol}^{-1}$ and an amylose content of approximately $33 \%$. Starch derivatives were prepared by TEMPO mediated oxidation ${ }^{22}$ of potato starch, resulting in a negatively charged starch derivative (NegSt). This well-known first oxidation step was also employed in order to further synthesize a positively charged starch derivative, via subsequent reaction of the carboxylic group of NegSt with the amine group of ethylenediamine (Scheme 1). The advantage of this initial oxidation process lies within the regioselectivity of the C-6 oxidation, which leads ultimately to a very controlled coupling product (PosSt). Positively charged starch (PosSt) was synthesized as mentioned by covalent coupling of ethylenediamine to the free acid form of oxidized starch, via a carbodiimide-mediated amidation. The method was adopted from Sheehan. ${ }^{24}$ The benefit of this reaction is the selectivity of the coupling between carboxylic and amine groups, so that no protection of the hydroxyl groups is necessary. Additionally, there are no toxic side products/impurities, as is the case for synthesis of cationic starches in the paper industry, where the substitution is generally performed with epoxyalkylamines ${ }^{25,26}$ or halogenalkylamines. ${ }^{27}$

After the oxidation of potato starch, ${ }^{1} \mathrm{H}-\mathrm{NMR}$ spectra of NegSt (Fig. S1, ESI $\dagger$ ) showed $\delta H$ values between 5.28-5.58 ppm, that were assigned to the anomeric $1 \mathrm{H}$ atom. The signals between 3.20-4.20 ppm were ascribed to the ring protons $2 \mathrm{H}, 3 \mathrm{H}$, $4 \mathrm{H}, 5 \mathrm{H}^{21,28}$ Following the reaction, the degree of oxidation (DSCOONa) was determined by a colorimetric assay, according to Blumenkrantz et al. ${ }^{23}$ Briefly, the Blumenkrantz assay detects uronic acid content (carboxylic groups arising from the TEMPO C-6 oxidation) by building a chromogen when heated in concentrated sulphuric acid/tetraborate and treated with $m$-hydroxydiphenyl. NegSt showed an oxidation degree of $40.32 \pm 0.01 \%$. The yield of 


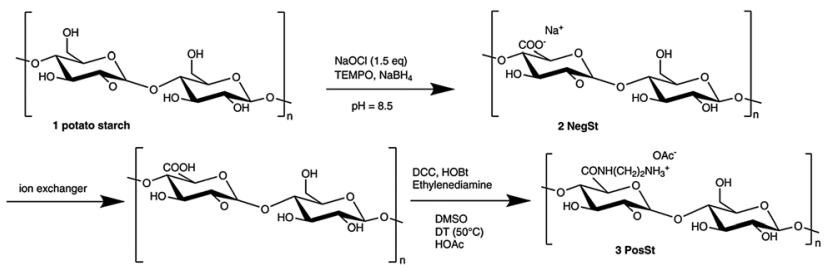

Scheme 1 Synthesis of negatively charged starch (NegSt) and positively charged starch (PosSt). Potato starch is illustrated as amylose.

this process was $80.6 \%$. The weight average molecular weight, determined by GPC was $87000 \pm 1800$ (Fig. S2, ESI $\dagger$ ).

The coupling reaction could be observed by ${ }^{1} \mathrm{H}-\mathrm{NMR}$ (Fig. S1, ESI $\dagger$ ). PosSt showed the typical pattern between 5.10-5.62 ppm of the anomeric $1 \mathrm{H}$ atom. The ring protons were visible between 3.30-4.30 ppm. Further, the value between 3.00-3.22 ppm was ascribed to the coupled ethylenediamine $\left(-\mathrm{NH}-\mathrm{CH}_{2}-\mathrm{CH}_{2}-\mathrm{NH}_{2}\right)$. FT-IR spectra confirm these results (Fig. 1): the typical peaks at $1600 \mathrm{~cm}^{-1}(\mathrm{C}=\mathrm{O}$ stretching of the carboxyl anion COONa) and $1732 \mathrm{~cm}^{-1}(\mathrm{C}=\mathrm{O}$ stretching from the $\mathrm{COOH}$ group, after ion exchange), were absent in PosSt. These were replaced by two peaks at $1660 \mathrm{~cm}^{-1}$ and at $1550 \mathrm{~cm}^{-1}$, resulting from amide bond formation - the amide I peak $\left(1660 \mathrm{~cm}^{-1}\right)$ is mainly associated with the $\mathrm{C}=\mathrm{O}$ stretching vibration, while the amide II peak $\left(1550 \mathrm{~cm}^{-1}\right)$ results from the $\mathrm{N}-\mathrm{H}$ bending vibration and from the $\mathrm{C}-\mathrm{N}$ stretching vibration. The reaction yield for the coupling with ethylenediamine was found to be $59.6 \%$ and the degree of coupling was $34.6 \%$, determined by ${ }^{1} \mathrm{H}$-NMR. GPC measurements showed a weight average molecular weight of $76000 \pm$ 4300 for PosSt (Fig. S2, ESI $\dagger$ ), which is in the same range as that found for NegSt.

\section{Starch nanoparticle preparation}

Starch NPs were prepared via charge-mediated coacervation in aqueous solution at RT, a process similar to the preparation of chitosan-TPP nanoparticles, introduced by Calvo et al. ${ }^{12,29}$ In contrast to the chitosan system, where a polymer (chitosan) is interacting with a small molecule (TPP), the starch NP formation involved the interaction of two polymeric materials of approximately the same molecular weight. Mixing the two oppositely charged starch derivatives under stirring led to the spontaneous formation of NPs, suggesting that partial charge neutralization occurred due to the reaction of positively

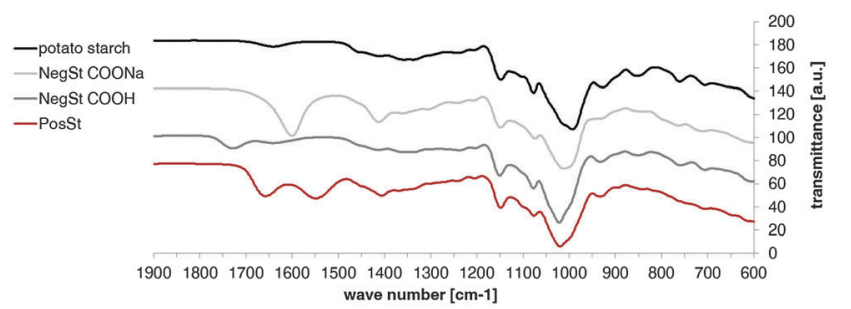

Fig. 1 FT-IR spectra of potato starch (black) and starch derivatives (dark red: PosSt; light grey: NegSt COONa; dark grey: NegSt $\mathrm{COOH}$ ). charged amine groups from PosSt with negatively charged carboxylic groups of NegSt. This process is very mild, as organic solvents, sonication, and high temperatures are avoided. Further, no additional excipients such as stabilizers are necessary for the NP preparation.

Different PosSt and NegSt concentrations $\left(1 \mathrm{mg} \mathrm{mL} \mathrm{m}^{-1}\right.$, $0.5 \mathrm{mg} \mathrm{mL}^{-1}, 0.25 \mathrm{mg} \mathrm{mL}^{-1}$ ) were employed for the preparation process. NegSt was added to PosSt in different molar ratios $(1: 3,1: 1,3: 1)$ with the help of a syringe pump under stirring. Important properties of the formed NPs, such as size, PdI and $\zeta$-potential are described in Table 1 , in relation to the used material concentrations and molar ratios. The PdI was always below 0.2 , indicating a narrow particle size distribution for all formulations. Particle size ranged from approximately 140 to $350 \mathrm{~nm}$, depending on both the molar ratio of components and concentration of solutions. The smallest particle size of $138.9 \pm 0.3 \mathrm{~nm}$ was obtained for $0.25 \mathrm{mg} \mathrm{mL}^{-1}$ concentrations and a molar ratio of $1: 3$. Keeping the molar ratio constant, but increasing the material concentrations to 0.5 and $1 \mathrm{mg} \mathrm{mL}^{-1}$ resulted in increased particle sizes of $160.5 \pm 0.6$ and $181.6 \pm$ $1.7 \mathrm{~nm}$, respectively. This is in accordance with Calvo et al., who obtained similar results (an increase of particle size with increasing material concentrations) for the interaction of chitosan with TPP. ${ }^{12}$ The utilized molar ratio was also seen to influence particle size. Looking again at $0.25 \mathrm{mg} \mathrm{mL} \mathrm{mL}^{-1}$ concentrations, an increase in particle size from $138.9 \pm 0.3 \mathrm{~nm}$ to $152.0 \pm 0.2 \mathrm{~nm}$, and further to $209 \pm 2.8 \mathrm{~nm}$ was observed for molar ratios of $1: 3,1: 1$ and $3: 1$, respectively. This indicated that with an increase in the content of PosSt, the particle size also increased.

In the investigated ratios, the $\zeta$-potential was between -35 and $-10 \mathrm{mV}$, and was found to vary depending only on the molar ratio of PosSt and NegSt. For all three tested material concentrations, the $\zeta$-potential was approximately $-35 \mathrm{mV}$ for a molar ratio of $1: 3$. A molar ratio of $1: 1$ resulted in a $\zeta$-potential of around $-25 \mathrm{mV}$, while starch NPs prepared in a molar ratio of $3: 1$ showed a $\zeta$-potential of around $-10 \mathrm{mV}$; therefore, the greater the amount of positively charged starch (PosSt) in the formulation, the closer the $\zeta$-potential was to 0 . All formulations showed a negative $\zeta$-potential, due to the fact that the degree of coupling with ethylenediamine was about $34.6 \%$, meaning there are still free carboxylic groups left in PosSt (oxidation degree of NegSt $\sim 40 \%$ ). NP formulations of $0.25 \mathrm{mg} \mathrm{mL}^{-1}$ were chosen for further experiments as a particle size of around $150 \mathrm{~nm}$ was desired.

For evaluating the storage stability of starch NPs, $0.25 \mathrm{mg} \mathrm{mL} \mathrm{m}^{-1}$ formulations with a molar ratio of $1: 3,1: 1$ and $3: 1$ were chosen, in order to investigate the influence of NP surface charge. Starch NPs showed different storage stabilities when stored after preparation: while starch 0.25-1:3 and starch $0.25-1: 1$ showed stability in size over 14 days, the formulation starch $0.25-3: 1$, with a $\zeta$-potential close to zero showed aggregation tendencies when stored at RT or at $4{ }^{\circ} \mathrm{C}$ (Fig. S4, ESI $\dagger$ ). Obviously, for this formulation the weak surface charge is not able to electrostatically stabilize the NP suspension via repulsive forces. ${ }^{30}$ 
Table 1 Physicochemical characteristics of starch NPs related to concentration of solutions used for complexation and molar ratio of components. The last three formulations (shown in bold) were used for further evaluation of starch NPs, of which one $\left({ }^{\mathrm{a}}\right.$ ) was used for biodegradation, protein loading, and uptake studies

\begin{tabular}{|c|c|c|c|c|c|c|}
\hline Formulation name & PosSt conc. $\left[\mathrm{mg} \mathrm{mL}^{-1}\right]$ & NegSt conc. $\left[\mathrm{mg} \mathrm{mL}^{-1}\right]$ & PosSt: NegSt [molar ratio] & Size $[\mathrm{d} n m]$ & PdI & $\zeta$-Potential $[\mathrm{mV}]$ \\
\hline Starch 1-1:1 & 1 & 1 & $1: 1$ & $206.9 \pm 0.7$ & 0.078 & $-22.2 \pm 0.1$ \\
\hline Starch $1-3: 1$ & 1 & 1 & $3: 1$ & $346.9 \pm 6.6$ & 0.211 & $-10.3 \pm 0.1$ \\
\hline Starch $0.5-1: 1$ & 0.5 & 0.5 & $1: 1$ & $179.0 \pm 1.6$ & 0.077 & $-23.5 \pm 0.8$ \\
\hline Starch $0.5-3: 1$ & 0.5 & 0.5 & $3: 1$ & $230.5 \pm 4.2$ & 0.084 & $-9.1 \pm 0.1$ \\
\hline Starch $0.25-1: 3$ & 0.25 & 0.25 & $1: 3$ & $138.9 \pm 0.3$ & 0.105 & $-37.0 \pm 3.1$ \\
\hline
\end{tabular}

\section{Morphology}

TEM images of starch NPs, prepared from $0.25 \mathrm{mg} \mathrm{mL}^{-1}$ solutions, incubated on a copper grid and stained with $1 \%$ PTA are shown in Fig. 2. For all formulations, black particles with a spherical, solid and consistent shape could be observed. Indicated sizes are comparable to gained Zetasizer data. Due to their gel-like, sticky character, NPs tended to aggregate during the drying process on the copper grid, forming a gel layer (data not shown). Therefore, starch NPs were positively stained and stabilized with $1 \%$ PTA during the drying process. While a considerable number of nanoparticles could be found for formulations starch $0.25-3: 1$ and starch $0.25-1: 1$, the formulation of starch $0.25-1: 3$ only showed few particles. The $\zeta$-potential of $-37.0 \pm 3.1 \mathrm{mV}$ probably hindered the ability of these particles to efficiently interact with the slightly negatively charged TEM grids during the incubation time.

\section{Cell viability assay}

For evaluating cell viability, A549 cells, representing a human pulmonary adenocarcinoma cell line, ${ }^{31}$ were incubated with starch NPs for $4 \mathrm{~h}$ and $24 \mathrm{~h}$ at $37{ }^{\circ} \mathrm{C}$. In order to investigate the influence of molar ratio on cell viability, three different starch NP formulations were studied: Starch $0.25-3: 1$, starch $0.25-$ $1: 1$, and starch $0.25-1: 3$. For comparison, NegSt, PosSt, and a water soluble potato starch (PSs) were tested. Concentrations were in a range from 8 to $133 \mu \mathrm{g} \mathrm{mL}{ }^{-1}$. Viability data of A549 cells after treatment with aforementioned samples for $4 \mathrm{~h}$ and $24 \mathrm{~h}$ can be found in Fig. 3 .

At the $4 \mathrm{~h}$ measurement, PSs and NegSt showed cell viabilities of around $100 \%$. PosSt showed a decrease in cell viability with increasing concentration, with a level of $65.4 \pm 5.5 \%$ noted for the highest tested concentration. Similar results were

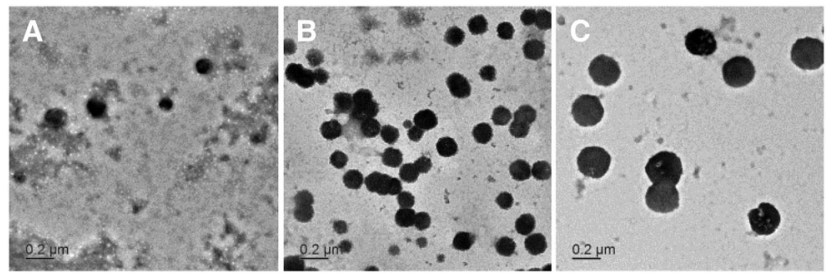

Fig. 2 TEM images of starch NPs, positively stained with 1\% PTA. (A) Starch 0.25-1:3; (B) starch 0.25-1:1; (C) starch 0.25-3:1.
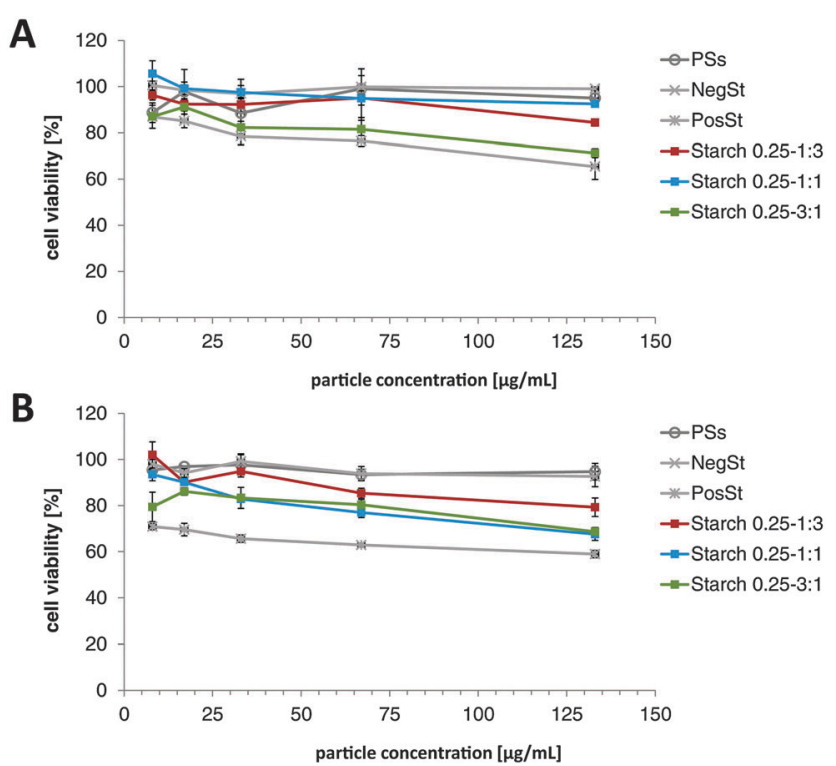

Fig. 3 Viability data of A549 cells after exposure to starch NPs, or starch derivatives (PosSt, NegSt), or a soluble potato starch (PSs) for $4 \mathrm{~h}$ (A) or $24 \mathrm{~h}$ (B). Data represent two independent experiments ( $n=3$ in each).

obtained for starch $0.25-3: 1$ with cell viabilities of around $71.3 \pm 1.9 \%$. Decreasing the PosSt amount in the NP formulation led to an increase in cell viability, which is not surprising bearing in mind that positively charged polymers usually show higher toxicities. ${ }^{20,32}$ The increase in toxicity after $24 \mathrm{~h}$ should be taken into consideration, but should not be overestimated, as degradation products usually show less toxicity compared to pure polymer - this could be shown by Yamada et al., ${ }^{20}$ with respect to the toxicity of starch-PEI derivatives and their degradation products. Further, the synthesized starch derivatives and prepared DDS showed higher cell viabilities as the starch-PEI derivatives from Yamada et al. for a comparable incubation time of $4 \mathrm{~h}$, indicating an advantage of our newly developed DDS. Considering that the 1:1 ratio showed good cell viability and good particle stability over time, this formulation was chosen for further experiments.

\section{Biodegradation}

When talking about health care applications of NPs, one important point that has to be considered is the biodegradation 
of the system. This is due to the fact that safety of NPs is not only related to their size, but also depends, amongst a number of other factors (toxicity of raw material, dose frequency, etc.), on their persistence in the body. The longer NPs stay in the body without any biodegradation, the higher the potential risk of adverse effects, e.g. due to unintentional stimulation of the immune system. ${ }^{33}$ Further, degradation products of NPs must also be sufficiently safe, as otherwise they may contribute to unwanted effects such as non-specific immune responses. Therefore, we selected starch derivatives as material for DDS preparation. Starch itself consists of glucose monomers only, which are known to be safe. Only some monomer units of PosSt show coupled ethylenediamine (34.6\%). This is further reduced by using a NP system, consisting of positively and negatively charged starch derivatives. In a proof of concept study, to show whether such NPs are degradable not only by unspecific degradation processes but also by a specific enzymatic degradation, we tested the biodegradability of starch nanoparticles by $\alpha$-amylase - an enzyme found for example in saliva, pancreatic juice and serum. ${ }^{34}$ It is even secreted in the lungs in a diseased state from carcinomas with adenomatous differentiation, ${ }^{35}$ which could additionally confer a targeting effect on the starch NPs.

Particle concentration was determined with the help of nanoparticle tracking analysis after several time points. Compared to a control group (starch NPs stored at $37{ }^{\circ} \mathrm{C}$ without enzyme), which showed particle concentrations fluctuating between $40-55 \times 10^{8}$ particles per $\mathrm{mL}$ over time, a drastic decrease in particle concentration, could be observed already after $2 \mathrm{~h}$ incubation with $\alpha$-amylase at $37{ }^{\circ} \mathrm{C}$ (Table 2). While it might be expected that modified starch is less effectively degraded by $\alpha$-amylase, and indeed Yamada et al. found that the biodegradation of modified starch-PEI derivatives by $\alpha$-amylase was slower compared to the degradation of unmodified starch; however, the starch derivatives were still able to be degraded by the enzyme. ${ }^{20}$ Furthermore, synthesized starch derivatives (NegSt, PosSt) in the current work represent a smaller change to the molecular structure of unmodified starch than starch-PEI derivatives, which have a relatively long molecular side chain. Accordingly, the incubation of starch NPs with $\alpha$-amylase showed that also after charge-mediated coacervation, NegSt and PosSt could not only be degraded by unspecific degradation processes for polysaccharides or potentially by intracellular enzymes, ${ }^{36,37}$ but also by the specific human enzyme $\alpha$-amylase.

\section{Stability of nanoparticles upon aerosolization}

The aerosolization properties of unlabeled and labeled starch NPs were investigated by nebulizing starch NP suspension, and

Table 2 Biodegradation of starch NPs by $\alpha$-amylase at $37^{\circ} \mathrm{C}$

\begin{tabular}{lll}
\hline & $\begin{array}{l}\text { Starch NPs }+ \text { amylase } \\
{\left[\times 10^{8} \text { particles per } \mathrm{mL}\right]}\end{array}$ & $\begin{array}{l}\text { Starch NPs } \\
{\left[\times 10^{8} \text { particles per } \mathrm{mL}\right]}\end{array}$ \\
\hline Before & $44.5 \pm 0.2$ & $41.1 \pm 0.7$ \\
$2 \mathrm{~h}$ & $2.7 \pm 0.6$ & $56.1 \pm 8.1$ \\
$4 \mathrm{~h}$ & $1.7 \pm 1.1$ & $45.8 \pm 1.7$ \\
$6 \mathrm{~h}$ & $1.8 \pm 0.8$ & $55.4 \pm 10.4$ \\
$8 \mathrm{~h}$ & $0.9 \pm 0.6$ & $50.2 \pm 4.4$
\end{tabular}

measuring NP physicochemical properties before and after nebulization. In Table 3 it can be seen that unlabeled starch NPs showed the same values before and after nebulization. The labeled starch NPs showed the same size and PdI, but exhibited a decrease in $\zeta$-potential following nebulization. The fluorescent dye may change the hydrophobicity of the NPs, and thus the tightness of the surface binding of the ion layers which contribute to the zeta potential.

\section{Uptake studies}

In order to evaluate uptake of starch NPs into A549 and $16 \mathrm{HBE} 14 \mathrm{o}^{-}$cells, PosSt was labeled with a green fluorescent dye (Bodipy ${ }^{\circledR}$ FL C5 NHS Ester), and starch NPs were prepared afterwards from $0.25 \mathrm{mg} \mathrm{mL}{ }^{-1}$ solutions in a ratio of $1: 1$. The size of these labeled starch NPs was $145.2 \pm 0.1 \mathrm{~nm}$, with a PdI of 0.1 , indicating a narrow size distribution. The $\zeta$-potential was $-26.4 \pm 2.8 \mathrm{mV}$. Starch NPs were deposited onto A549 cells and further incubated for $1 \mathrm{~h}, 4 \mathrm{~h}$ and $24 \mathrm{~h}$ at $37^{\circ} \mathrm{C}$. As control, A549 cells were grown under ALI conditions without treatment. Endocytosis, as an energy-driven uptake mechanism, is highly reduced in cells at $4{ }^{\circ} \mathrm{C}$; therefore, NP incubation was also evaluated at $4{ }^{\circ} \mathrm{C}$ for the A549 cell line (Fig. S6, ESI $\dagger$ ). If NPs are taken up by the cells at $4{ }^{\circ} \mathrm{C}$, it can be concluded that the uptake is not by an endocytosis-mediated mechanism. The uptake of starch NPs by A549 cells can be seen in Fig. 4A-D. Particles (green) already showed a level of uptake into A549 cells after $1 \mathrm{~h}$ of incubation at $37{ }^{\circ} \mathrm{C}$. There was also some uptake after $1 \mathrm{~h}$ of incubation at $4{ }^{\circ} \mathrm{C}$, although to a lower extent, suggesting that at least a part of the uptake mechanism is energy dependent (i.e. occurs by endocytosis). The cell associated fluorescence as observed at $4{ }^{\circ} \mathrm{C}$ could also be due to mere binding to the cell membrane, in addition to or instead of indicating some nonspecific, energy independent uptake. Such nonspecific uptake is however known for A549 cells, suggesting that this could be a cell-dependent phenomenon. ${ }^{38}$

Additionally, the interaction of starch NPs with $16 \mathrm{HBE}^{-} \mathrm{o}^{-}$ cells, a cell line generated by transformation of normal human bronchial epithelial cells that does not show carcinoma like properties, ${ }^{39,40}$ was also tested. The results of this study can be found in Fig. 4E-H. The size of starch NPs in this case was $114.6 \pm 2 \mathrm{~nm}$, with a PdI of 0.12 and a $\zeta$-potential of $-28.1 \pm$ $0.6 \mathrm{mV}$. As can be seen from Fig. $4 \mathrm{E}-\mathrm{H}$, the nucleus staining was more intense, whereas the actin staining showed a decreased fluorescence in comparison to the A549 cells. No particle uptake was seen after $1 \mathrm{~h}$ of incubation. However, after

Table 3 Physicochemical properties of unlabeled and labeled starch NPs before and after nebulization, prepared from $0.25 \mathrm{mg} \mathrm{mL}^{-1}$ solutions in a molar ratio of $1: 1$. Fluorescently labeled $\mathrm{PosSt}_{F}$ was $50 \%$ of the PosSt amount

\begin{tabular}{llll}
\hline Starch NPs & Size $[\mathrm{d} \mathrm{nm}]$ & PdI & $\zeta$-Potential $[\mathrm{mV}]$ \\
\hline Before & $168.7 \pm 2.1$ & 0.09 & $-19.4 \pm 4.9$ \\
After & $167.4 \pm 7.2$ & 0.09 & $-21.2 \pm 2.2$ \\
& & & \\
Labeled before & $145.2 \pm 0.7$ & 0.1 & $-26.4 \pm 2.8$ \\
Labeled after & $145.2 \pm 2.2$ & 0.09 & $-14.9 \pm 6.6$
\end{tabular}



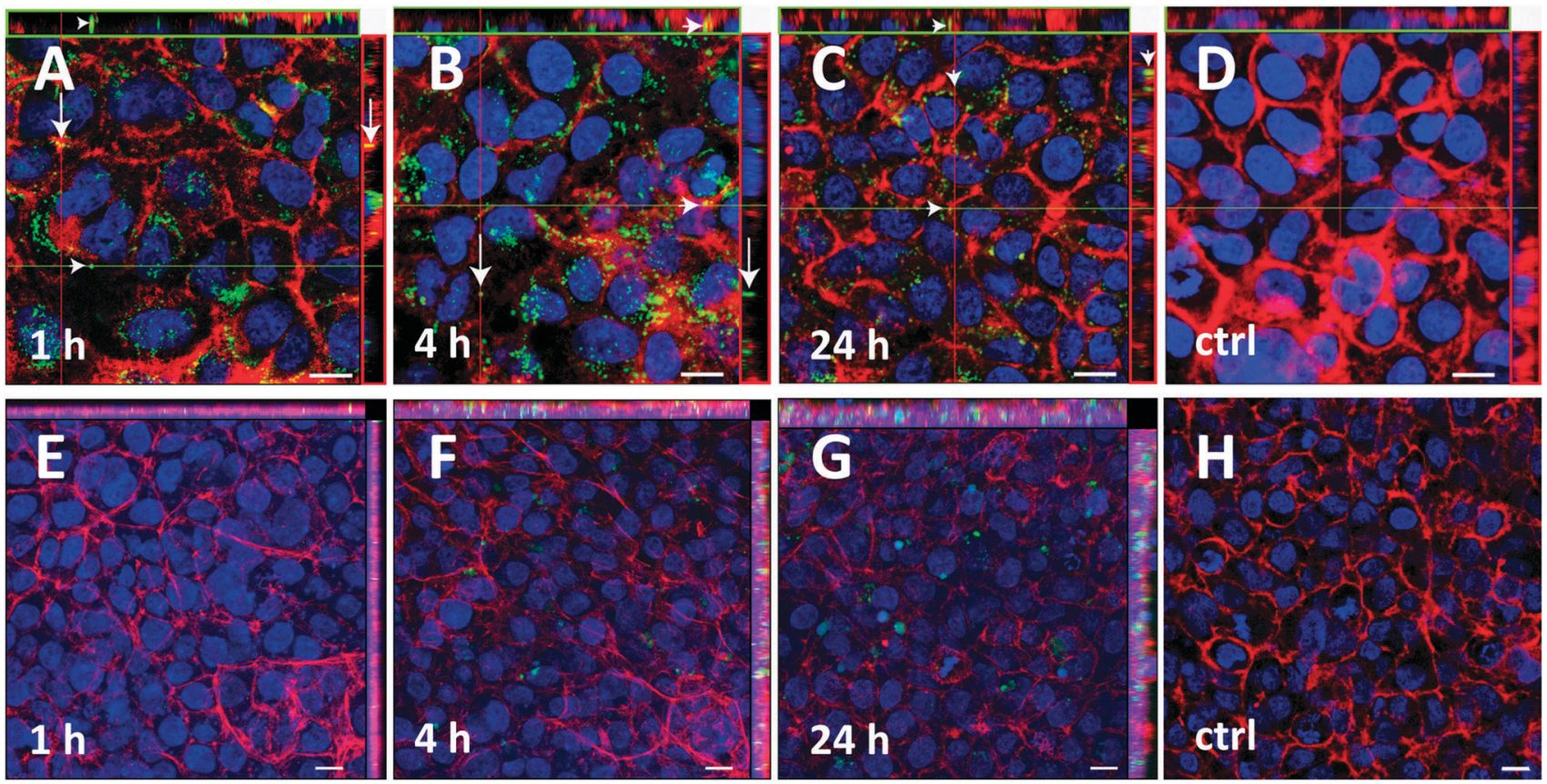

Fig. 4 Confocal laser scanning microscopy (CLSM) images of $250 \mu \mathrm{L}$ nebulized starch NP onto A549 (upper row) and $16 \mathrm{HBE140^{- }}$ (lower row) cells, cultivated under ALI at $37^{\circ} \mathrm{C}$. (A) After $1 \mathrm{~h}$ incubation; (B) after $4 \mathrm{~h}$ incubation; (C) after $24 \mathrm{~h}$ incubation; (D) control; (E) after $1 \mathrm{~h}$ incubation; (F) after $4 \mathrm{~h}$ incubation; $(G)$ after $24 \mathrm{~h}$ incubation; $(\mathrm{H})$ control. Cells were washed with PBS, fixed with 3\% PFA and stained. Blue: DAPl; red: actin; green: starch NP; scale bar: $10 \mu \mathrm{m}$; arrow: extracellular NPs; arrow head: intracellular NPs.

an incubation time of $4 \mathrm{~h}$ or longer some particles could be observed and seem to be localized below the cell membrane, despite the non-optimal membrane staining. The apparent lower extent of particle uptake into $16 \mathrm{HBE}_{14 \mathrm{o}^{-}}$cells compared to A549 cells should be judged with caution.

The confocal microscopy analysis shown here, provides qualitative data. The amount of uptake cannot be directly compared between the two cell types since the particle batch and the instrument settings (e.g. laser power) were not identical. An important factor in uptake studies is the proliferation rate of the cell line. A549 is a fast growing cancer cell line with a doubling time of $22 \mathrm{~h}$. The non-cancerous $16 \mathrm{HBE}^{-} 14 \mathrm{o}^{-}$cells are somewhat slower in growth with $26 \mathrm{~h}$ doubling time, a fact which may contribute to the apparently different uptake rate and speed. Despite being non quantitative, these experiments show a potential of uptake of starch NPs into two cell lines of pulmonary origin.

\section{Loading}

To investigate the use of starch NPs as DDS, a protein test set was created. This included four different proteins of different isoelectric points (IEPs) and molecular weights, which could also be potential drug candidates. Such proteins were to be tested in vitro for their efficiency in a next step. The selected proteins were IgG1 $\left(M_{\mathrm{w}}: 150 \mathrm{kDa}\right.$, IEP: 8.5$)$, RNAse A $\left(M_{\mathrm{w}}: 14 \mathrm{kDa}\right.$, IEP: 9.6), insulin ( $M_{\mathrm{w}}: 6 \mathrm{kDa}$, IEP: 5.3), and vancomycin $\left(M_{\mathrm{w}}: 1.5 \mathrm{kDa}\right.$, IEP: 7.5). For this experiment, starch NPs from $0.25 \mathrm{mg} \mathrm{mL}^{-1}$ solutions and a molar ratio of $1: 1$ were chosen, as these showed the best stability and a medium level, negative $\zeta$-potential of around $-25 \mathrm{mV}$. Table 4 shows the physical properties of protein-loaded starch NPs as well as EE and loading rate, as determined indirectly with the BCA assay after separating loaded NPs from free protein via ultracentrifugation. The EE and loading rate were different for all four proteins. The EE was affected by the initial amount of protein: the lower the amount, the higher the EE. Conversely, the loading rate was enhanced by increasing the initial amount of protein. Calvo et al. observed the same phenomenon for the encapsulation of BSA into chitosan NPs. ${ }^{12}$ A narrow size distribution (low PdI) could be observed for all formulations, except for the formulation loaded with $500 \mu \mathrm{g}$ IgG1. An increase in size, combined with a decrease in $\zeta$-potential indicated that the loading with IgG1 was successful. It seems that the loading can be increased from approximately $4.5 \%$ (125 $\mu \mathrm{g}$ and $250 \mu \mathrm{g}$ IgG1) up to $12.0 \%$ for the $500 \mu \mathrm{g}$ formulation. However, when taking into account the broad size distribution of 0.39 , such data must be interpreted cautiously. As the EE was obtained via indirect measurement, protein aggregation could have biased the results. A saturation of IgG1 loading could already be seen for the $125 \mu \mathrm{g}$ formulation, as no difference could be found between the encapsulated mass and the loading rate of the $125 \mu \mathrm{g}$ loaded $\mathrm{NP}$ and the $250 \mu \mathrm{g}$ loaded NP. For these formulations the encapsulated mass was found to be 63 and $72 \mu \mathrm{g}$, respectively, and the loading was determined as 4.4 and $4.9 \%$ respectively.

Starch NPs loaded with RNAse A showed no saturation, as the loading could be increased from $4.9 \%$ for the $250 \mu \mathrm{g}$ loaded formulation up to $9.6 \%$ for the $750 \mu \mathrm{g}$ formulation, however, the EE dropped from $27.9 \%$ down to $18.1 \%$. The same could be observed for insulin: an EE of $24.9 \%$ for the loading with $250 \mu \mathrm{g}$ of insulin decreasing to $15.9 \%$ for the loading with $750 \mu \mathrm{g}$ 
Table 4 Physicochemical properties, encapsulation efficiency (EE) and loading of starch nanoparticles loaded with different amounts of IgG1, RNAse A, insulin or vancomycin

\begin{tabular}{|c|c|c|c|c|c|c|c|}
\hline Starch NP (loaded with) & Mass $_{\text {initial }}$ protein $(\mu \mathrm{g})$ & Size $[\mathrm{d} n m]$ & PdI & $\zeta$-Potential [mV] & Mass $_{\text {encaps }}$ protein $(\mu \mathrm{g})$ & $\mathrm{EE}[\%]$ & Loading rate $[\%]$ \\
\hline Blank & - & $157.7 \pm 2.2$ & 0.08 & $-23.7 \pm 0.7$ & - & - & - \\
\hline \multicolumn{8}{|l|}{ IgG1 ( $M_{\mathrm{w}} 150 \mathrm{kDa}$, IEP 8.5) } \\
\hline & 125 & $179.6 \pm 6.1$ & 0.10 & $-18.0 \pm 0.2$ & $63.2 \pm 14.7$ & $50.6 \pm 11.7$ & $4.4 \pm 1.0$ \\
\hline & 250 & $237.4 \pm 15.6$ & 0.17 & $-13.1 \pm 0.3$ & $71.9 \pm 1.9$ & $28.8 \pm 0.8$ & $4.9 \pm 0.1$ \\
\hline & 500 & $556.5 \pm 49.5$ & 0.39 & $-11.6 \pm 0.9$ & $174.3 \pm 2.4$ & $35.9 \pm 0.5$ & $12.0 \pm 0.2$ \\
\hline \multicolumn{8}{|c|}{ RNAse A ( $M_{\mathrm{w}} 14 \mathrm{kDa}$, IEP 9.6) } \\
\hline & 250 & $171.5 \pm 0.3$ & 0.07 & $-21.6 \pm 0.6$ & $72.0 \pm 3.4$ & $27.9 \pm 1.3$ & $4.9 \pm 0.2$ \\
\hline & 500 & $172.9 \pm 1.3$ & 0.05 & $-17.7 \pm 2.4$ & $103.5 \pm 3.1$ & $20.1 \pm 0.6$ & $7.1 \pm 0.2$ \\
\hline & 750 & $195.0 \pm 31.5$ & 0.13 & $-20.7 \pm 0.5$ & $139.8 \pm 20.5$ & $18.1 \pm 2.7$ & $9.6 \pm 1.4$ \\
\hline \multicolumn{8}{|l|}{ Insulin ( $M_{\mathrm{w}} 6 \mathrm{kDa}$, IEP 5.3$)$} \\
\hline & 250 & $157.6 \pm 0.7$ & 0.09 & $-22.7 \pm 1.2$ & $62.4 \pm 3.1$ & $24.9 \pm 1.2$ & $4.3 \pm 0.2$ \\
\hline & 500 & $162.3 \pm 0.4$ & 0.06 & $-21.0 \pm 0.3$ & $73.9 \pm 4.7$ & $14.8 \pm 0.9$ & $5.1 \pm 0.3$ \\
\hline & 750 & $160.3 \pm 0.9$ & 0.07 & $-20.4 \pm 0.5$ & $119.2 \pm 4.3$ & $15.9 \pm 0.6$ & $8.2 \pm 0.3$ \\
\hline \multicolumn{8}{|c|}{ Vancomycin $\left(M_{\mathrm{w}} 1.5 \mathrm{kDa}\right.$, IEP 7.5) } \\
\hline & 250 & $163.9 \pm 0.4$ & 0.08 & $-23.4 \pm 0.7$ & $205.2 \pm 7.7$ & $81.1 \pm 3.0$ & $14.2 \pm 0.5$ \\
\hline & 500 & $164.7 \pm 0.8$ & 0.05 & $-21.2 \pm 0.3$ & $258.6 \pm 0.2$ & $51.1 \pm 0.1$ & $17.8 \pm 0.1$ \\
\hline & 750 & $164.5 \pm 0.6$ & 0.06 & $-21.2 \pm 0.4$ & $330.1 \pm 4.1$ & $43.5 \pm 0.5$ & $22.8 \pm 0.3$ \\
\hline
\end{tabular}

insulin, together with an increase in loading from $4.3 \%$ up to $8.2 \%$. The most promising loading, however, was achieved for vancomycin, which showed loading efficiencies of up to $22.8 \%$ for the $750 \mu \mathrm{g}$ loaded formulation, together with a high EE of $43.5 \%$.

The differences in EE and loading rate can be ascribed to the differences in IEP and molecular weight. Calvo et al., among others, described the phenomenon of protein loading as electrostatic interaction between protein and polysaccharide. ${ }^{12}$ As the loading of the proteins into the starch NPs is a result of the electrostatic interactions between negatively charged NPs and protein, the IEP of each protein at the $\mathrm{pH}$ of the starch NP suspension ( $\mathrm{pH}$ 7.4) has to be taken into account. Both IgG1 and RNAse A are positively charged at $\mathrm{pH}$ 7.4, whereas insulin is negatively charged and vancomycin is neutral. A high EE and loading for IgG1 and RNAse A would therefore be expected. However, IgG1 and RNAse A loaded starch NP showed rather low loading capacities of $4.9 \%$ and $9.6 \%$, respectively. The slightly higher loading of RNAse could be due to the fact that the system loaded with IgG1 was already saturated in the case of the $250 \mu \mathrm{g}$ formulation. IgG1 is an antibody with a molecular weight of around $150 \mathrm{kDa}$, and therefore requires more space when binding to the NP surface than e.g. RNAse A, with a molecular weight of around $14 \mathrm{kDa}$. Insulin showed a similar behavior to RNAse A: a loading of $8.2 \%$ could be achieved for the $750 \mu \mathrm{g}$ formulation, although insulin is negatively charged at $\mathrm{pH}$ 7.4. Vancomycin, which is neutral at $\mathrm{pH} 7.4$, showed the highest loading of $22.8 \%$, probably due to a combined effect of low water solubility at this $\mathrm{pH}$, as well as a low molecular weight of $1.5 \mathrm{kDa}$.

\section{Conclusions}

The derivatization of potato starch into water soluble, positively and negatively charged starches enabled the formation of starch NPs in aqueous medium via charge-mediated coacervation.
NPs with a spherical shape could be obtained. Physicochemical properties of NPs could be tuned by varying concentration and molar ratio of the two starch components. In a proof of concept study, the chosen NP formulation was seen to be biodegradable by $\alpha$-amylase, and showed little cytotoxicity after $4 \mathrm{~h}$. NPs were stable during nebulization and were observed to be taken up by A549 cells, largely by endocytosis. Further, the preparation of starch NPs allowed for loading of proteins/peptides of different molecular weights and IEPs under mild conditions. Vancomycin showed the highest loading rate (23\%) and $\mathrm{EE}(44 \%)$, probably favored by the combination of the low molecular weight and the hydrophobicity of that particular compound. It can therefore be concluded that starch NPs prepared by such an eco-friendly and easy technique have the potential to be further explored as safe platform for pulmonary delivery of proteins and peptides. To further ensure protein stability during storage and administration and a high alveolar deposition, NPs could be embedded into microparticles.

\section{Acknowledgements}

The authors thank Dr C. Thiele for optimizing the synthesis, Dr J. Zapp for the NMR data, and Dr R. Haberkorn for performing the XRPD experiments. Dr S. Gordon is thanked for proof reading the manuscript. The work was supported by the Innovative Medicines Initiative Joint Undertaking under grant agreement No. 115363, a resource which is composed of financial contributions from the European Union's Seventh Framework Programme (FP7/2007-2013) and in kind contributions from companies of the EFPIA.

\section{Notes and references}

1 S. Lawrence, Nat. Biotechnol., 2005, 23, 1466.

2 G. Walsh, Nat. Biotechnol., 2006, 24, 769-776. 
3 S. Mitragotri, P. A. Burke and R. Langer, Nat. Rev. Drug Discovery, 2014, 13, 655-672.

4 S. Frokjaer and D. E. Otzen, Nat. Rev. Drug Discovery, 2005, 4, 298-306.

5 J. L. Cleland, A. Daugherty and R. Mrsny, Curr. Opin. Biotechnol., 2001, 12, 212-219.

6 G. Orive, R. M. Hernández, A. R. Gascón, A. Domínguez-Gil and J. L. Pedraz, Curr. Opin. Biotechnol., 2003, 14, 659-664.

7 M. B. Brown, G. P. Martin, S. A. Jones and F. K. Akomeah, Drug Delivery, 2006, 13, 175-187.

8 R. Duncan, Nat. Rev. Cancer, 2006, 6, 688-701.

9 M. L. Houchin and E. M. Topp, J. Pharm. Sci., 2008, 97, 2395-2404.

10 O. Germershaus, T. Lühmann, J. C. Rybak, J. Ritzer and L. Meinel, Int. Mater. Rev., 2015, 60, 101-131.

11 M. Rajaonarivony, C. Vauthier, G. Couarraze, F. Puisieux and P. Couvreur, J. Pharm. Sci., 1993, 82, 912-917.

12 P. Calvo, C. Remunan-Lopez, J. L. Vila-Jato and M. J. Alonso, J. Appl. Polym. Sci., 1997, 63, 125-132.

13 A. Grenha, C. I. Grainger, L. A. Dailey, B. Seijo, G. P. Martin, C. Remuñán-López and B. Forbes, Eur. J. Pharm. Sci., 2007, 31, 73-84.

14 G. Coppi, V. Iannuccelli, E. Leo, M. T. Bernabei and R. Cameroni, Drug Dev. Ind. Pharm., 2001, 27, 393-400.

15 K. A. James, M. P. Fresneau, A. Marazuela, A. Fabra and M. J. Alonso, J. Controlled Release, 2001, 73, 255-267.

16 M. Günbeyaz, A. Faraji, A. Özkul, N. Puralı and S. Şenel, Eur. J. Pharm. Sci., 2010, 41, 531-545.

17 A. Bozkir and O. M. Saka, Drug Delivery, 2004, 11, 107-112.

18 S. Mansouri, Y. Cuie, F. Winnik, Q. Shi, P. Lavigne, M. Benderdour, E. Beaumont and J. C. Fernandes, Biomaterials, 2006, 27, 2060-2065.

19 M. J. Santander-Ortega, T. Stauner, B. Loretz, J. L. OrtegaVinuesa, D. Bastos-González, G. Wenz, U. F. Schaefer and C. M. Lehr, J. Controlled Release, 2010, 141, 85-92.

20 H. Yamada, B. Loretz and C.-M. Lehr, Biomacromolecules, 2014, 15, 1753-1761.

21 C. Thiele, D. Auerbach, G. Jung, L. Qiong, M. Schneider and G. Wenz, Polym. Chem., 2011, 2, 209-215.
22 P. L. Bragd, A. C. Besemer and H. Bekkum, Carbohydr. Res., 2000, 328, 355-363.

23 N. Blumenkrantz and G. Asboe-Hansen, Anal. Biochem., 1973, 54, 484-489.

24 J. C. Sheehan and G. P. Hess, J. Am. Chem. Soc., 1955, 77, 1067-1068.

25 T. Shiroza, K. Furihata, T. Endo, H. Seto and N. Otake, Agric. Biol. Chem., 1982, 46, 1425-1427.

26 E. F. Paschall, US Pat., US2876217 A, 1959.

27 G. C. Carlyle and O. B. Wurzburg, US Pat., US2813093 A, 1957.

28 Y. Kato, R. Matsuo and A. Isogai, Carbohydr. Polym., 2003, 51, 69-75.

29 P. Calvo, C. Remunan-Lopez, J. L. Vila-Jato and M. J. Alonso, Pharm. Res., 1997, 14, 1431-1436.

30 J. Jiang, G. Oberdörster and P. Biswas, J. Nanopart. Res., 2008, 11, 77-89.

31 D. J. Giard, S. A. Aaronson, G. J. Todaro, P. Arnstein, J. H. Kersey, H. Dosik and W. P. Parks, J. Natl. Cancer Inst., 1973, 51, 1417-1423.

32 M. Huang, E. Khor and L. Y. Lim, Pharm. Res., 2004, 21, 344-352.

33 C. M. Keck and R. H. Müller, Eur. J. Pharm. Biopharm., 2013, 84, 445-448.

34 J. J. Zakowski and D. E. Bruns, Crit. Rev. Clin. Lab. Sci., 1985, 21, 283-322.

35 P. Lenler-Petersen, A. Grove, A. Brock and R. Jelnes, Eur. Respir. J., 1994, 7, 941-945.

36 S. Mahadevan, C. J. Dillard and A. L. Tappel, Arch. Biochem. Biophys., 1969, 129, 525-533.

37 B. Winchester, Glycobiology, 2005, 15, 1R-15R.

38 H. Herd, N. Daum, A. T. Jones, H. Huwer, H. Ghandehari and C. M. Lehr, ACS Nano, 2012, 7, 1961-1973.

39 B. Forbes, A. Shah, G. P. Martin and A. B. Lansley, Int. J. Pharm., 2003, 257, 161-167.

40 C. Ehrhardt, C. Kneuer, J. Fiegel, J. Hanes, U. F. Schaefer, K. J. Kim and C. M. Lehr, Cell Tissue Res., 2002, 308, 391-400. 